
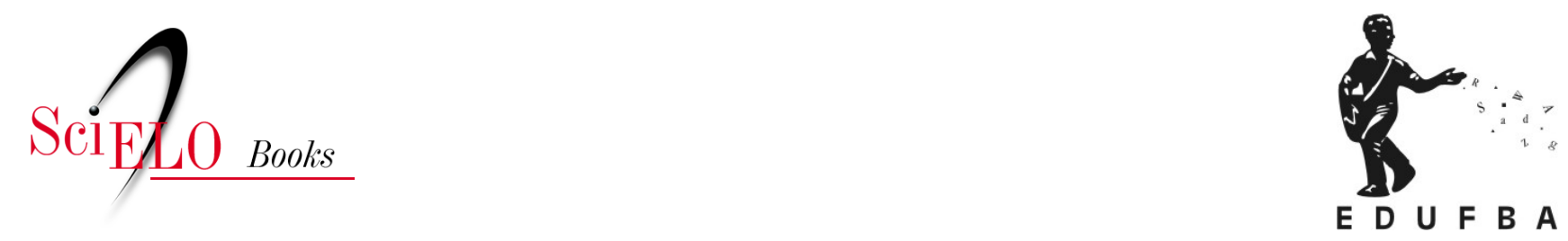

\title{
Agências multilaterais de desenvolvimento e comunidades epistêmicas
}

\author{
Anete B. L. Ivo
}

\section{SciELO Books / SciELO Livros / SciELO Libros}

IVO, A.B.L., ed. Agências multilaterais de desenvolvimento e comunidades epistêmicas. In: $A$ reinvenção do desenvolvimento: agências multilaterais e produção sociológica [online]. Salvador: EDUFBA, 2016, pp. 13-36. ISBN: 978-85-232-1857-7. https://doi.org/10.7476/9788523218577.0002.

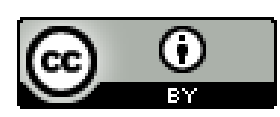

All the contents of this work, except where otherwise noted, is licensed under a Creative Commons Attribution $\underline{4.0 \text { International license. }}$

Todo o conteúdo deste trabalho, exceto quando houver ressalva, é publicado sob a licença Creative Commons Atribição 4.0. 


\title{
AGÊNCIAS MULTILATERAIS DE DESENVOLVIMENTO E COMUNIDADES EPISTÊMICAS ${ }^{1}$
}

\author{
Anete B. L. Ivo
}

As mudanças do Estado desenvolvimentista, na década de noventa e dois mil, integram um novo regime de acumulação global, sob a hegemonia do mercado, e impõem processos de reforma dos Estados (nacionais) na área social e de ajuste fiscal, considerados como "inovações" institucionais na medida em que produzem inflexões nos pilares do Welfare e no pacto social e político entre trabalhadores assalariados, empresários e Estados do pós-Segunda Guerra.

Essa transição reorienta as formas de mediação do conflito redistributivo entre ativos e trabalho, e implica uma "virada" epistemológica que reforça paradigmas "solidaristas" e institucionais de integração das massas populares ao mercado, formas cooperativas entre setores públicos e privados, ou cooperação entre países, ou seja, promove arranjos de governança pactuados entre agências multilaterais, Estados nacionais, mercado e sociedade civil, em diversas escalas. No plano cognitivo, essas transformações redefinem problemáticas sociais, ou impõem reflexões críticas da agenda de pesquisa, especialmente orientada para observar os seus efeitos no âmbito da política, da estrutura social e do encaminhamento das questões sociais. 
Este texto visa a apresentar, ainda de forma preliminar, as normativas difundidas pelas agências internacionais de desenvolvimento, particularmente o Banco Mundial (BM) e o Programa das Nações Unidas para o Desenvolvimento (PNUD), com base em seus relatórios anuais. $O$ entendimento é de que a ação dessas agências se articula ao contexto político e econômico da reforma neoliberal, seja na produção de "consensos relativos"2 aos regimes de ação favoráveis à integração das camadas sociais empobrecidas ao mercado, num contexto de crescimento, ou, inversamente, na sua contraposição, pela formulação crítica a essa nova ordem social, em grande parte produzida por análises das ciências sociais.

Portanto, os novos sentidos da noção do desenvolvimento na agenda internacional, nos anos noventa e dois mil, além de imperativos econômicos, políticos, sociais e ideológicos, implicam também uma dimensão cognitiva. Em que campos temáticos as agências multilaterais reorientam o sentido e as ações para o desenvolvimento no período de 1990 a 2014? Que problemas são tratados, que mediações são postas do ponto de vista das inovações institucionais na agenda dos países e qual a sua função na produção do conhecimento? Este texto integra o projeto $A$ reinvenção do desenvolvimento: agências multilaterais e a produção sociológica contemporânea apoiado pelo Edital Universal n. 14 do CNPq (2012) e busca oferecer elementos contextuais que possibilitem entender a dinâmica de um regime de ação para o desenvolvimento, no âmbito global, com base nas normativas do Banco Mundial e do Programa das Nações Unidas, no período. Ao final levanta algumas hipóteses sobre as relações ambíguas entre esses regimes de ação, a produção da política em diferentes escalas e o campo das ciências sociais, ou seja, busca desvelar novas relações dialéticas e conflitivas entre saber e poder.

\section{A ação das agências internacionais nos anos 1990-2014}

Para os agentes econômicos, a década de 1980 foi considerada como a "década perdida", devido à estagnação econômica dos países 
da América Latina, com retração da produção industrial, volatilidade dos mercados e redução do ritmo do crescimento. A constituição de uma nova agenda internacional, na década de 1990, parte de um diagnóstico crítico dessa crise e recomenda novos arranjos institucionais de inspiração liberal e conservadora para enfrentá-la, como o ajuste fiscal dos Estados (nacionais) e as ações de governança em escalas locais e global no encaminhamento de problemas globais, a exemplo dos programas de combate à pobreza e de proteção ao meio ambiente. Para entender os significados dessa agenda, o texto apresenta o repertório temático das agências internacionais e como elas emergem como atores fundamentais no contexto dos anos 1990 e 2000, na difusão de ideias para a pactuação de um novo desenvolvimento "global".

As Nações Unidas, o Banco Mundial (BM) e o Banco Internacional de Desenvolvimento (BID) têm atuado na difusão de ideias e orientações sobre "temáticas conflitivas" entre países, - tais como danos ambientais, avanços da pobreza e a desigualdade entre países, segurança, especialmente em regime de paz -, redefinindo a necessidade de um novo padrão de "cooperação", seja em termos de responsabilidades compartilhadas entre o setor público e o privado, seja na formação de coalizões geopolíticas regionais entre países, na perspectiva de inovações institucionais, econômicas e sociais.

A seguir, apresentam-se os objetivos e os âmbitos de atuação do BM e do PNUD, de forma a identificar semelhanças e diferenças entre as agendas propostas e observar elementos do modus operandi adotado nos anos 1990-2014, tomando por base definições encontradas nos sites dessas agências.

\section{- O Banco Mundial}

O Banco Mundial (BM) é uma instituição especializada da Organização das Nações Unidas (ONU) que congrega 187 países-membros. O Banco está sediado em Washington e seu presidente é eleito pelo Conselho de Administração para um mandato de cinco anos. O principal papel do Banco é ajudar financeiramente os países em vias de desenvolvimento nas áreas de educação, agricultura, indústria e saúde. 
O Banco articula cinco instituições de caráter financeiro voltadas para ajudar economicamente os países, do ponto de vista de uma agenda de crescimento, via empréstimos a aqueles países de renda média e aos mais pobres, ajudando-os a superarem os óbices ao crescimento. Além desse fomento mercantil, o Banco também funciona na arbitragem de diferenças entre agentes, em relação a investimentos. São instituições que compõem o Banco Mundial:

- O Banco Internacional para a Reconstrução e o Desenvolvimento (BIRD), criado em 1944 e que reúne 187 países. Ele tem por objetivo reduzir a pobreza nos países com renda intermediária e nos mais pobres, mas solventes, por via de empréstimos e garantias, com base em seus instrumentos de gestão de riscos e serviços de análise e dos conselhos. O essencial dos recursos do BIRD origina-se dos mercados de capitais mundiais, mas vem também de emprestadores (mutuários) mais conhecidos.

- A Sociedade Financeira Internacional (IFC), que financia empréstimos e fundos próprios que visam a favorecer o investimento privado nos países em desenvolvimento. Criada em 1956, ela conta com 184 países-membros e se constitui na mais importante instituição mundial de ajuda ao desenvolvimento das atividades do setor privado.

- A Associação Internacional para o Desenvolvimento (IDA), que foi fundada em 1960 e reúne 165 países membros. Ela atua na concessão de empréstimos e subvenções a programas, visando a estimular o crescimento econômico. Ela também pode fazer doações para os países mais pobres.

- O Centro Internacional para Arbitragem de Disputas sobre Investimentos (CIRDI), que é uma instituição independente e congrega 140 países-membros. Seu objetivo é fornecer meios de reconciliação e arbitragem das diferenças relativas aos investimentos internacionais. O CIRDI entrou em ação em 1966 e, hoje, 
é considerado como a principal instituição internacional dedicada à regulação das diferenças entre investidores e Estados.

- A Agência Multilateral de Garantias dos Investimentos (MIGA), cuja missão é promover os investimentos diretos nos países em desenvolvimento para ajudar a sustentar o crescimento econômico e reduzir a pobreza. A Agência foi criada em 1988, sendo a mais jovem dentre as cinco instituições que compõem o BM, contando atualmente com 154 membros.

Em relação ao financiamento, o BM é composto por um Conselho de Governantes e outro Conselho de Chefes e Executivos para cada uma das agências que compõem o banco. Os cinco países que mais contribuem financeiramente no BIRD e possuem votos proporcionais às suas contribuições, são: EUA (16,53\%); Japão (7,93\%); Alemanha (4,53\%) Reino Unido (4,34\%) e França (4,34\%). (CAVALCANTI, 2008) Essa participação indica forte hegemonia dos EUA e do Japão nas decisões. Alemanha, França e Reino Unido alcançam, juntos, 13,09\% e não chegam ao percentual de participação dos EUA.

\section{- O Programa das Nações Unidas para o Desenvolvimento (PNUD)}

O PNUD é um dos principais organismos multilaterais de desenvolvimento, presente em mais de 170 países e territórios. Ele busca contribuir para erradicar a pobreza e reduzir as desigualdades e exclusões. Na forma como ele enuncia:

Nós ajudamos os países a elaborar políticas, a desenvolver competências e atitudes na formação de liderança e parcerias, a reforçar suas capacidades institucionais e a compartiIhar de soluções para problemas concernentes às seguintes questões:

- Desenvolvimento sustentável

- Governança democrática 
- Clima e adaptação

Em todas as nossas atividades estimulamos a proteção dos direitos do homem e a participação ativa das muIheres.

Num mundo com recursos limitados, o PNUD e seus parceiros apoiam a utilização mais eficaz dos recursos internacionais da ONU alocados para o desenvolvimento. Em cada um dos escritórios do PNUD, os seus representantes coordenam atividades e iniciativas em matéria de desenvolvimento do sistema das Nações Unidas, cuidando para garantir a integração estratégica do país no contexto internacional.

O PNUD administra igualmente um Fundo de Equipamento das Nações Unidas, que ajuda os países em desenvolvimento no crescimento de suas economias, complementando as fontes existentes de ajuda ao desenvolvimento com subvenções e empréstimos, além do apoio do programa de Voluntários das Nações Unidas (VNU), que aglutina mais de 6.000 voluntários originários de 160 países, atuando pela paz e pelo desenvolvimento no mundo inteiro.

O Relatório Mundial sobre o Desenvolvimento Humano, elaborado anualmente pelo PNUD, estimula o debate sobre as principais questões do desenvolvimento, na agenda internacional, desde 1990. Com base na experiência adquirida nos territórios de atuação e sua expertise acumulada no tema do desenvolvimento, o PNUD apoia esforços que visam a atingir os Objetivos do Desenvolvimento do Milênio (ODM) até 2015 , em cada país, e definir um programa de desenvolvimento sustentável para o pós-2015.

A Cúpula do Milênio das Nações Unidas, seguindo a filosofia do PNUD, definiu esses objetivos e metas, visando a: "Civilizar a economia mundializada ou garantir que a mundialização se torne uma força positiva para todos os povos do mundo" (Declaração do Milênio, adotada pela Cúpula do Milênio das Nações Unidas, 6 a 8 de setembro de 2000).

Os ODM, adotados pelos 191 Estados-membros das Nações Unidas, constituem, portanto, uma agenda ambiciosa para reduzir a 
pobreza, suas causas e manifestações, envolvendo compromissos de países e governos com políticas sociais voltadas para o enfrentamento dos oito objetivos (metas) a serem atingidos até 2015 (New York, setembro 2000):

- Reduzir a pobreza - Reduzir à metade a proporção da população cuja renda é inferior a um dólar por dia e a proporção de pessoas que passam fome.

- Atingir o ensino básico universal - Assegurar a educação primária a todos.

- Igualdade entre os sexos e a autonomia das mulheres - Eliminar as disparidades entre os sexos no ensino primário e secundário (até 2005) e, se possível, em todos os níveis até 2015.

- Reduzir a mortalidade na infância - Reduzir em dois terços a taxa de mortalidade das crianças com menos de cinco anos.

- Melhorar a saúde materna - Reduzir em três quartos a taxa de mortalidade materna.

- Combater o HIV/AIDS, a malária e outras doenças - Acabar com a propagação da AIDS, controlar o paludismo e outras graves doenças e começar a inverter a tendência atual.

- Garantir a sustentabilidade ambiental - Assegurar um meio ambiente viável, integrando os princípios do desenvolvimento sustentável nas políticas e programas nacionais e invertendo a tendência atual de desperdício dos recursos ambientais.

- Estabelecer uma parceria mundial para o desenvolvimento Implementar parcerias (cooperações) para o desenvolvimento.

\section{Principais temas de atuação do PNUD}

São três os campos de atuação do PNUD,que se expressam também em metas sociais para viabilizar os ODM: o desenvolvimento sustentável; a governança democrática e a adaptação dos países aos riscos de catástrofes, como condições básicas de erradicação da pobreza e enfren- 
tamento dos riscos ambientais, num contexto de crescimento econômico, governança e parceria democrática.

\section{- Desenvolvimento sustentável}

O objetivo do PNUD, nesse campo, é estimular a transição do desenvolvimento, evitando danos irreversíveis ao meio ambiente e fazendo com que o crescimento beneficie também os grupos pobres e marginalizados.

Para tanto, o PNUD ajuda os países a lutarem contra dois problemas associados: a) pobreza, a desigualdade e a exclusão, envolvendo ou desenvolvendo capacidades, ou seja, os conhecimentos, competências e tecnologias para preservar os ganhos do desenvolvimento; e b) a integração das questões ambientais nos planos e estratégias nacionais de desenvolvimento, ajudando os países a realizarem reformas, inovações, parcerias e financiamento, de forma a gerar empregos e garantir segurança social.

\section{- Governança democrática}

Um segundo campo de ação diz respeito a arranjos institucionais de governança democrática. Nessa área, o objetivo do PNUD visa a oferecer serviços eficazes e equânimes a todos os cidadãos e reforçar o Estado de direito e a seguridade, ajudando as instituições de governança local a se tornarem inclusivas e responsáveis. Para alcance desse objetivo, o PNUD apoia as instituições em reformas constitucionais, na organização de eleições legítimas, no reforço dos parlamentos, de modo a encontrarem soluções práticas na promoção da paz, na redução dos riscos, favorecendo o desenvolvimento com base em ações de negociação, reconciliação, autonomização e inclusão dos agentes.

\section{- Clima e adaptação}

A ação do PNUD, nesse eixo temático, consiste em integrar os problemas do clima, os riscos de catástrofes e a energia em escala nacional, de forma a reforçar a capacidade de adaptação dos países para garantir que o desenvolvimento seja sustentável e que se leve em conta os riscos. Isso porque os efeitos da mudança climática e a exposição 
crescente aos riscos de catástrofes ameaçam comprometer décadas de progresso em matéria do desenvolvimento e de esforços visando à erradicação da pobreza. Por essa razão, a adaptação e a redução dos riscos de catástrofes fazem parte da agenda do desenvolvimento do PNUD.

\section{As agendas das duas agências internacionais: Banco Mundial e Programa das Nações Unidas para o Desenvolvimento}

A relação entre globalização e desenvolvimento mostra tendências na ordem econômica mundial, sob a forma de processos interativos entre nações e agências internacionais de desenvolvimento, que atuam numa nova "mudança provocada". Essa mudança ocorre não mais exclusivamente sob o protagonismo do planejamento governamental nacional, como na década de 1960, mas na disseminação de diretrizes e metas das agências de desenvolvimento internacional, pactuadas com os Estados. Tais metas atendem às recomendações do Consenso de Washington, e implicam redução de responsabilidade dos Estados (nacionais) ou partilhas de responsabilidades entre agentes públicos e privados na agenda social, associada à tendência de liberdade do mercado dos capitais.

Os problemas do desenvolvimento, na década de 1990, especialmente nos anos 1992, consistem, portanto, em formas de interdependência dos países numa economia globalizada e no fluxo de capitais segundo a orientação do mercado livre, o que envolve fortes ajustes institucionais do Estado nacional em favor dessas orientações, as quais, segundo alguns especialistas, configuram formas indiretas de interferência sobre a soberania desses países, como analisam Osmond (1998) e Ivo (1998).

A noção de "sustentabilidade", que acompanha os pactos internacionais e as recomendações contra riscos ambientais, supõe o reconhecimento de uma tensão preexistente da transferência de riscos entre países ricos e pobres, além do impacto e da gestão de riscos dos grandes projetos sobre os territórios, especialmente aqueles em infra- 
estrutura, como energia. Tais projetos contrapõem empresas, governos e populações tradicionais preexistentes, como microagricultores, comunidades indígenas e outros grupos sociais ocupantes desses territórios, no que diz respeito à contrapartida de garantia de direitos dessas populações.

A agenda da luta contra a pobreza - objeto de discussão de cúpulas e tema dos relatórios das agências - tem influenciado o tratamento das políticas sociais pela via de programas sociais focalizados de transferência de renda e de democratização do crédito para as camadas populares, estimulando-se a economia pela inserção das famílias no âmbito do consumo e apoio ao empreendedorismo das classes populares.

As "inovações" no enfrentamento da pobreza combinam, portanto, dois paradigmas articulados. ${ }^{3}$ De um lado, há o paradigma de capacidades humanas e atendimento das necessidades básicas (Amartya Sen, PNUD), segundo o qual as estruturas reprodutivas das comunidades mais pobres devem ser reapropriadas como "ativos" no estímulo a processos de desenvolvimento local, mesmo em situação de vulnerabilidade e pobreza extrema. Há, portanto, o deslocamento de uma abordagem da redistribuição, própria do tratamento da economia política, para a ênfase em mecanismos estratégicos microssociais de inserção das famílias no mercado. Desloca-se, desse modo, a "polarização de conflitos" para um quadro de pactuação e responsabilidades partilhadas dos agentes sociais, em lógicas de expansão das atividades econômicas pelo consumo. Já a intervenção pública das políticas sociais pela via da transferência focalizada de renda orienta-se segundo um paradigma da escolha pública racional, e mobiliza dispositivos estáticos e focalizados de tratamento do social, subordinados estrategicamente ao cumprimento de metas orçamentárias predefinidas. Atua sobre estratos de renda mais baixa, definidos com base na noção de pobreza absoluta de renda. Tais políticas dissociam operações dinâmicas e relativas da pobreza e das desigualdades de renda, desvinculando-se da inserção dessas camadas no mercado de trabalho. Desconsideram-se, portanto, as relações intrínsecas entre 
produção e reprodução das camadas de trabalhadores em condições de extrema pobreza, que compõem segmentos de trabalhadores autônomos e trabalhadores por conta própria do mercado de trabalho urbano.

Durante a década de noventa, a agenda do PNUD tratou das seguintes temáticas: a introdução de uma nova noção de desenvolvimento, como "Desenvolvimento Humano" (DH), assentada na noção de capacidades humanas e na afirmação dos Direitos Humanos, criando-se um indicador sintético e comparativo dos países em termos socioeconômicos, o Índice de Desenvolvimento Humano (IDH); o financiamento do desenvolvimento humano; a contraposição entre a dinâmica do crescimento e fatores inerentes ao desenvolvimento humano (como pobreza, consumo e segurança); a assimetria entre os gêneros como dimensão das desigualdades; um padrão internacional do desenvolvimento e prognósticos para o novo século, em termos da mundialização da economia; e a participação popular na sustentação dessas capacidades e no desenvolvimento humano (Quadro 1).

Quadro 1 - Agenda temática das agências internacionais (Década de 1990)

\begin{tabular}{|l|l|l|}
\hline ANO & PNUD & BANCO MUNDIAL \\
\hline 1990 & Conceito e medição do desenvolvimento humano & \\
\hline 1991 & Financiamento do desenvolvimento humano & \\
\hline 1992 & Dimensões internacionais do desenvolvimento humano & Desenvolvimento e meio ambiente \\
\hline 1993 & Participação popular & Investindo em saúde \\
\hline 1994 & Novas dimensões da segurança humana & Infraestrutura para o desenvolvimento \\
\hline 1995 & Gênero e desenvolvimento humano & Trabalho num mundo integrado \\
\hline 1996 & Crescimento econômico e desenvolvimento humano & Do plano ao mercado \\
\hline 1997 & Desenvolvimento humano para erradicar a pobreza & O Estado num mundo de mudanças \\
\hline 1998 & Consumo para o desenvolvimento humano & Entrando no Século XXI \\
\hline 1999 & Mundialização com humano & idem \\
\hline
\end{tabular}

Fontes: elaboração do autor (2015) com base em Relatórios sobre o Desenvolvimento Mundial (1992-1999) e sobre o Desenvolvimento Humano do Banco Mundial (1990-1999).

O Banco Mundial iniciou a divulgação do seu relatório anual a partir de 1992. As temáticas tratadas referem-se ao enfrentamento 
da questão ambiental, à infraestrutura para o desenvolvimento, às redefinições do papel do Estado, à privatização de serviços e à reorientação do trabalho numa economia globalizada.

É singular que a agenda de Desenvolvimento Humano não trate de questões relativas ao conflito redistributivo, como as desigualdades de renda e o trabalho, centrais aos regimes de crescimento (o trabalho assume, então, uma noção abstrata de "formador de renda"). Na realidade, a noção do desenvolvimento do PNUD, na década de 1990, parte de uma crítica ao economicismo apoiado exclusivamente na renda, considerado restritivo, deslocando a dimensão da redistribuição dos ativos nacionais para o âmbito das capacidades individuais em termos de atributos ou capacidades humanas para a liberdade (a formação de sujeitos autônomos). Pode-se, então, levantar a hipótese de que a noção de desenvolvimento humano, traduzida como valores e atributos individuais qualificadores da dimensão humana, fora da matriz conflitiva dos direitos sociais, teria função pacificadora num regime de crescimento e acumulação, podendo mistificar o conflito entre ativos e trabalho e o acesso aos direitos sociais pela noção fundante dos direitos humanos como valores intrínsecos à dimensão do desenvolvimento social. A agenda do Banco Mundial parece indicar os pilares da transição no período, em termos da discussão de temas relativos a: infraestrutura, reforma e ajustes institucionais do Estado, transferência dos serviços básicos e públicos para o mercado, contradições do trabalho num regime globalizado de acumulação, além de preparação da mudança para o século XXI (Quadro 1).

Nos anos 2000, o PNUD associa à agenda da pobreza também algumas dimensões políticas, como democracia, formas de luta e resiliência na articulação entre sustentabilidade e equidade no monitoramento de bens escassos, como a água, no reconhecimento da ascensão do bloco de países do Sul e na cooperação entre países.

O Banco Mundial inicia a década acompanhando a agenda do PNUD no enfrentamento da luta contra a pobreza. ${ }^{4} \mathrm{Em} 2013$, em razão da crise de 2008 e das formas de resiliência daí resultantes, apresenta um balanço financeiro, orienta a construção de serviços para o merca- 
do, retorna à questão do conflito ambiental e da desigualdade entre os gêneros (como parâmetros de equidade) e ao enfrentamento de questões do trabalho (Quadro 2).

Quadro 2 - Agenda temática das agências internacionais (2000-2014)

\begin{tabular}{|c|c|c|}
\hline ANO & PNUD & BANCO MUNDIAL \\
\hline 2000 & Direitos humanos e desenvolvimento humano & Enfrentando a pobreza \\
\hline 2001 & $\begin{array}{l}\text { Colocar o avanço tecnológico à serviço do } \\
\text { desenvolvimento humano }\end{array}$ & Idem \\
\hline 2002 & $\begin{array}{l}\text { Aprofundar a democracia em um mundo } \\
\text { fragmentado }\end{array}$ & Construindo instituições para o mercado \\
\hline 2003 & $\begin{array}{l}\text { Os Objetivos do Desenvolvimento do Milênio: } \\
\text { um pacto entre as nações para eliminar a } \\
\text { pobreza }\end{array}$ & $\begin{array}{l}\text { Desenvolvimento sustentável num } \\
\text { mundo dinâmico }\end{array}$ \\
\hline 2004 & A liberdade cultural no mundo diverso de hoje & Produzindo serviços para pessoas pobres \\
\hline 2005 & $\begin{array}{l}\text { A cooperação internacional diante de uma } \\
\text { encruzilhada: ajuda ao desenvolvimento, } \\
\text { comercio e segurança em um mundo desigual }\end{array}$ & $\begin{array}{l}\text { Um melhor investimento climático para } \\
\text { todos }\end{array}$ \\
\hline 2006 & $\begin{array}{l}\text { Para alem da escassez: poder, pobreza e crise } \\
\text { mundial da água }\end{array}$ & Equidade e desenvolvimento \\
\hline $2007 / 2008$ & $\begin{array}{l}\text { A luta contra a mudança climática: solidariedade } \\
\text { frente a um mundo dividido }\end{array}$ & [2007] Demonstração financeira \\
\hline 2008 & - & Agricultura e desenvolvimento \\
\hline 2009 & $\begin{array}{l}\text { Superando barreiras: mobilidade e } \\
\text { desenvolvimento humanos }\end{array}$ & $\begin{array}{l}\text { Disparidade espacial e política de } \\
\text { desenvolvimento }\end{array}$ \\
\hline 2010 & $\begin{array}{l}\text { A verdadeira riqueza das nações: caminhos ao } \\
\text { desenvolvimento humano }\end{array}$ & Desenvolvimento e mudança climática \\
\hline 2011 & $\begin{array}{l}\text { Sustentabilidade e equidade: um melhor futuro } \\
\text { para todos }\end{array}$ & Conflito, segurança e desenvolvimento \\
\hline 2012 & - & Gênero, igualdade e desenvolvimento \\
\hline 2013 & $\begin{array}{l}\text { A ascensão do Sul: } \\
\text { Progresso humano num mundo diversificado }\end{array}$ & Trabalho \\
\hline 2014 & $\begin{array}{l}\text { Sustentando o progresso humano: redução da } \\
\text { vulnerabilidade e construção da resiliência }\end{array}$ & Riscos e oportunidades \\
\hline
\end{tabular}

Fontes: elaboração do autor (2015) com base em Relatórios sobre o Desenvolvimento Mundial e sobre o Desenvolvimento Humano do Banco Mundial (2000-2014).

Comparando as agendas, observa-se que não há uma linearidade temporal entre ambas, mas uma complementação entre elas: enquanto o BM trata mais do crescimento econômico e da regulação financeira nos países, o PNUD assume a responsabilidade de uma agenda "social", em termos de valores do desenvolvimento "humano", 
enfrentamento das desigualdades de gênero e participação política, mas não trata dos direitos sociais e do trabalho.

O tratamento conceitual e metodológico do desenvolvimento humano produz uma reorientação conceitual, não mais se reportando aos padrões redistributivos, mas às desigualdades culturais, de gênero, ou aos déficits de acesso das pessoas às capacidades universais (educação e saúde), considerando-as como capitais sociais e ativos. A tradução dessas preocupações em metas se expressa nos ODM. Eles operam a agenda social na forma de obrigações pactuadas entre os países quanto a: saúde, educação, desigualdades entre sexos e gerações, meio ambiente e paridade dos países na sua inserção na ordem mundial.

A estratégia do Brasil, do ponto de vista do Banco Mundial, envolve: (i) reformas e modernização do Estado; (ii) melhorias de competitividade e acesso do mercado produtivo brasileiro; (iii) redução das desigualdades e da pobreza; (iv) promoção do manejo ambiental e dos recursos naturais de acordo com a Country Assistance Strategy (CAP) do BID, especificada em Cavalcanti (2008).

Os relatórios do PNUD, no Brasil, tratam de temas sociais estratégicos para o país, tais como: (i) 1996: desafios estratégicos das desigualdades (no âmbito municipal) em termos de educação, combate à pobreza, expansão do emprego e gestão ambiental; (ii) 2005: desigualdade racial em todos os indicadores, considerando os negros como o segmento mais vulnerável da população; (iii) 2009-2010: os valores e o desenvolvimento humano, com base num levantamento qualitativo que examina a 'política como valor', definindo conceitualmente o que são valores, suas medidas, bem como a relação conflitiva desses valores e a educação; os valores e a violência (Quadro 3). Ambas as agências induzem sistemas de avaliação sistemáticos no acompanhamento institucional dos programas, que induzem gradativamente à formação de um amplo consenso sobre a pertinência e aprovação dessas políticas sociais pelos agentes institucionais envolvidos, como analisa Lautier (2010). 
Quadro 3 - Agenda de desenvolvimento humano do PNUD, no Brasil, 1996-2010

\begin{tabular}{|c|c|c|}
\hline ANO & $\begin{array}{l}\text { TEMA } \\
\text { INTERNACIONAL }\end{array}$ & TEMA DH - BRASIL \\
\hline 1996 & $\begin{array}{l}\text { Crecimiento } \\
\text { económico y } \\
\text { desarrollo humano }\end{array}$ & $\begin{array}{l}\text { PRINCIPAIS QUESTÕES SOCIAIS DO BRASIL: DESIGUALDADES } \\
\text { ENTRE MUNICÍPIOS. } \\
\text { Desafios estratégicos resultantes do modelo de crescimento } \\
\text { implementado no Brasil para as áreas de educação, combate à } \\
\text { pobreza, expansão do emprego e gestão ambiental. } \\
\text { Aborda questões da natureza institucional, focalizando a } \\
\text { necessidade de reconstrução do Estado e o crescente papel } \\
\text { desempenhado pela sociedade civil organizada. }\end{array}$ \\
\hline 2005 & $\begin{array}{l}\text { La cooperación } \\
\text { internacional ante } \\
\text { una encrucijada: } \\
\text { ayuda al desarrollo, } \\
\text { comercio y } \\
\text { seguridad en un } \\
\text { mundo desigual }\end{array}$ & $\begin{array}{l}\text { RACISMO, POBREZA E VIOLÊNCIA. } \\
\text { Analisa as desigualdades raciais em termos de renda, educação, } \\
\text { saúde, emprego, habitação e violência, e conclui que os negros } \\
\text { estão em situação pior em todos os indicadores. } \\
\text { Aborda os mitos raciais surgidos ao longo da história brasileira - } \\
\text { como o racismo científico e a democracia racial } \\
\text { Analisa a história e os desafios do movimento negro no país e a } \\
\text { pobreza política a que a população negra está submetida. }\end{array}$ \\
\hline $2009-2010$ & $\begin{array}{l}\text { Superando barreras: } \\
\text { movilidad y } \\
\text { desarrollo humanos } \\
\text { La verdadera } \\
\text { riqueza de las } \\
\text { naciones: caminos al } \\
\text { desarrollo humano }\end{array}$ & $\begin{array}{l}\text { VALORES E DESENVOLVIMENTO HUMANO } \\
\text { Consulta pública realizada pela campanha Brasil Ponto a Ponto, } \\
\text { que levou uma pergunta aberta à população brasileira: } \\
\text { "O que precisa mudar no Brasil para sua vida melhorar de } \\
\text { verdade?" } \\
\text { Examina conceitualmente o que são valores, suas medidas e a } \\
\text { relação entre valores e educação; valores e violência. } \\
\text { Trata das políticas de valor. } \\
\text { Oferece uma proposta analítica para a formulação de novos } \\
\text { índices de desenvolvimento humano para o Brasil. }\end{array}$ \\
\hline
\end{tabular}

Fonte: elaboração do autor (2015) com base em informações disponíveis no site do PNUD no Brasil.

\section{A formação de uma comunidade epistêmica}

Comparando as temáticas dos relatórios analisados, pode-se afirmar que os temas têm impacto na difusão de novas ideias, orientando uma "nova ordem social e econômica", pela definição de parâmetros e compromissos dos Estados em escala mundial. Apesar de o 
Banco Mundial induzir reformas do Estado (nacional) em favor da liberalização dos mercados, ele também reconhece o poder desses Estados ao lhes atribuir um papel estratégico na abertura de mercados, no âmbito internacional. Por outro lado, a noção de good governance, no âmbito global, atua na mediação de assimetrias entre os países e nas contradições entre a economia e a política, na forma de negociações e responsabilização de países na cooperação interblocos geopolíticos, garantindo formas de consentimento em favor do mercado e do seu programa de ação. Nesses acordos, os dispositivos morais assumem uma "representação virtuosa" de engajamento cívico, que evolui do plano individual dos sujeitos comprometidos na edificação de uma agenda (supostamente) "justa e eficaz", que circula em diferentes escalas, desde a internacional às comunidades locais.

Mediante esses processos e recursos ideológicos, forma-se o que Peter Haas (1992) chama de comunidade epistêmica, em favor da agenda da transição liberal, composta por uma rede de profissionais com conhecimento e habilidades no manejo de programas de combate à pobreza e redução de riscos ambientais, em todo o mundo, os quais influenciam governos na aplicação de tecnologias sociais de gestão da pobreza, organização e capacitação dos agentes, promovendo a transferência de conhecimentos e uma socialização gradativa dos agentes nacionais e ONGs com esses novos valores das agências internacionais. Eles compartilham "crenças" que fornecem os fundamentos morais, técnicos e políticos, "num movimento amplo de construção do consentimento como forma de hegemonia", como analiso em Ivo (2005).

Essa comunidade epistêmica viabiliza processos de transição da ordem social e consolida fundamentos e modelos de intervenção estratégica no âmbito de Estados, municipalidades e famílias, a exemplo dos programas focalizados de transferência de renda, de economia solidária etc.

Como exemplo desse processo, os economistas do Banco Mundial elaboram modelos de projeções em relação ao mercado mundial, bem como prospecções e evolução dos indicadores que servem de base para o planejamento de políticas nacionais, em diversos países 
e estudos. Do mesmo modo, o PNUD mobiliza conhecimentos da comunidade científica, a exemplo do trabalho de Amartya Sen, como fundamento para a construção do Índice de Desenvolvimento Humano, que passa a se constituir parâmetro de hierarquização dos países em termos de equidade e avaliação de políticas sociais.

A importância do Banco, no âmbito da difusão de estudos, pode ser avaliada porseus investimentos na área de pesquisa. De acordo com Stern e Ferreira (1997),

[...] só o setor de pesquisa do Banco aloca recursos que ultrapassam US\$ 25 milhões, além de distribuir e disponibilizar mais de um milhão de livros e artigos. Ele [o Banco] possui um catálogo com mais de 500 títulos que chega a vender entre US\$ 10 milhões a 30 milhões por ano.

O montante do investimento em agendas e conhecimento (na geração de ideias) pode ultrapassar expectativas de qualquer universidade, segundo Cavalcanti (2008).

Não se pode, pois, deixar de considerar a influência dessas agendas sobre o universo do conhecimento produzido pela comunidade científica em todo o mundo. Essa comunidade de pesquisadores e consultores interage com essas diretrizes, redefinindo prioridades da ação social e medidas de eficácia em termos do encaminhamento de questões sociais, a exemplo, no Brasil, de estudos sobre desigualdades, com ênfase nas relações raciais e na crise de valores, bem como na relação conflitiva entre educação e violência.

Do ponto de vista da produção das ciências sociais, observa-se um modus operandi das agências internacionais na orientação aos governos, em suas políticas, que forma consensos, define regimes de ação e redesenha novos problemas e desafios de pesquisa. Entretanto, essa influência não é unilateral, pois envolve também a crítica e a contestação dos limites dessa agenda. Essa dinâmica associa mudanças "locais" e "nacionais" na interface com os Estados e com a ordem global, mas essa interação, mesmo orientada segundo teses difundidas por essas 
agências, não é homogênea, e responde a condições históricas e institucionais preexistentes nos países, a exemplo da questão das relações raciais na agenda do PNUD no Brasil.

\section{Algumas hipóteses preliminares}

A confluência entre atores internacionais e agendas de pesquisa, na produção do conhecimento sobre o desenvolvimento, se faz, indiretamente, pelo filtro dos governos e das organizações não governamentais, em ritmos diversos. Por exemplo, as recomendações de adaptação dos países aos riscos, formulada em 2014, é consequente com a ação anterior dos movimentos ambientais e de vários fóruns de discussão sobre o meio ambiente, que resultaram em análises da comunidade acadêmica. Nesse caso, a agenda formulada pela sociedade e os movimentos sociais, as demandas sociais e políticas e a produção acadêmica teriam anterioridade (4) e seriam filtradas pelas agências multilaterais em novas formas regulatórias e normativas, na busca de formação de "consensos relativos". Portanto, a relação entre agências internacionais, ação dos Estados e a produção do conhecimento se orienta por relações dialéticas e contraditórias, na dinâmica entre a ação social e contestatória dos agentes, a área de pesquisa das ciências sociais e a agenda temática repactuada das agências multilaterais, que estabelece novos regimes de ação. Como proposto na metodologia do projeto A reinvenção do Desenvolvimento: agências multilaterais e produção sociológica.

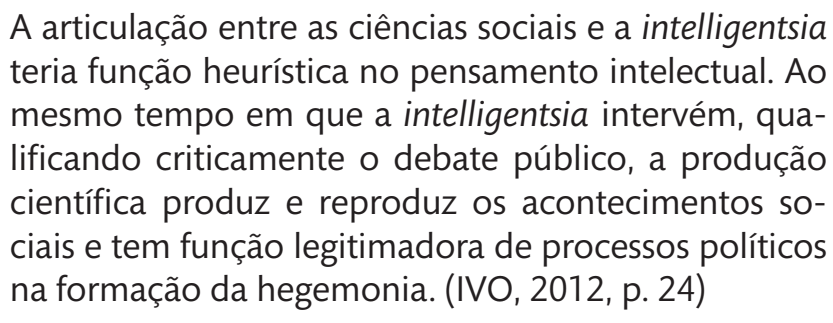

Não há, portanto, uma determinação verticalizada e linear nessa relação, mas a influência estratégica de regimes de ação dos atores 
internacionais associados a agentes públicos e sociais dos Estados em processos de formação da hegemonia e contra hegemonia. ${ }^{5}$ Nos anos 1990, eles orientam ajustes institucionais do Estado, especialmente na área social, e a desregulação do mercado, liberando os capitais de quaisquer limites e formas regulatórias pelos países; nos anos 2000 assumem uma agenda social na luta contra a pobreza, diante dos efeitos desagregadores e dessocializadores do mercado de trabalho, resultantes da aplicação dos ajustes fiscais; e, na década de 2010, definem uma agenda explícita de enfrentamento das questões ambientais e seus riscos, num quadro claramente conflitivo, considerando-se o contexto da crise estrutural de 2008 e repactuam formas cooperativas entre países do Sul e do Norte num processo de reconfiguração geopolítica. Essa reorientação envolve o reconhecimento implícito, pelas agências, das assimetrias e movimentos entre blocos de países em termos de padrões de crescimento, níveis de desigualdades, danos ambientais e pobreza.

A análise da produção sociológica, sistematizada com base nos grupos de pesquisa na área da sociologia do desenvolvimento (IVO, 2014), fez emergir temas estratégicos e subcampos da pesquisa sociológica do desenvolvimento, no contexto presente, que estabelecem conexões com as temáticas tratadas pelas agências internacionais, fazendo surgir novas regulações e conflitos, e também novas problemáticas de pesquisa do desenvolvimento, diferentes daquelas que prevaleciam na década de 1960.

Isso significa que as questões diagnosticadas e agendadas como prioritárias, em escala internacional, são relevantes para entender novas relações entre agentes (pesquisadores, agentes de governos etc.) e atores no quadro institucional. A produção acadêmica realizada, no entanto, nem sempre expressa uma "redução" da pesquisa a esquemas e sentidos propostos pelas agências internacionais. Ao contrário, muitos trabalhos dialogam com esses dispositivos de uma perspectiva crítica, demonstrando as tensões e assimetrias subjacentes a esses regimes de ação pactuados e os movimentos de hegemonia e contra hegemonia. 
A tematização das pesquisas com base nos grupos existentes no CNPq explicitou novas polaridades na dinâmica do desenvolvimento, em termos da divisão internacional do trabalho no mercado globalizado, que atualiza formas assumidas pelo capital na exploração de commodities, alterando, por exemplo, as pautas clássicas de prioridade dos estudos urbanos e rurais da década de 1960, nucleados pelo papel difusor da indústria no modelo de substituição de importações, à época. Também explicita novos modos de organização do trabalho, reorientando formas prioritárias do emprego urbano assalariado dos anos 1960, para reforçar análises sobre formas de empreendedorismo e empregabilidade das camadas populares, em conexão com a agenda internacional contemporânea do Banco Mundial, por exemplo, entre outras questões.

Assim, a análise da agenda das agências multilaterais sugere formas complexas de sua difusão e assimilação, tanto na ação pública e social como nas análises acadêmicas, nas quais a "inovação", nos arranjos institucionais propostos, reorienta formas mediadoras do conflito e regimes de ação em paradigmas de cooperação entre agentes públicos e privados, e entre blocos de países e para os quais se constitui como mediadora fundamental a chamada "comunidade epistêmica".

Por outro lado, temas diretamente articulados aos novos paradigmas do desenvolvimento - como os programas de transferência de renda na erradicação da pobreza e políticas sociais - não se articulam ao subcampo da sociologia do desenvolvimento, mas a estudos sobre políticas públicas ou sociais, arranjos de governança ou associativismo, por exemplo. As questões relativas a participação, governança e capital social e redes, ainda que componham o campo de tratamento de alguns GPs da subárea da sociologia do desenvolvimento, são articuladas também ao campo da representação política, do desenvolvimento local ou das políticas urbanas.

Assim, ainda que as conexões entre as agências internacionais multilaterais, uma agenda social nos países e a produção sociológica sejam mais complexas, é inquestionável o papel normativo e operativo das agencias internacionais multilaterais na reorientação de várias 
questões sociológicas (desenvolvimento local, desenvolvimento social e humano, programas focalizados, empreendedorismo, questão ambiental, governança local, formas de cooperação e arranjos entre agentes, tanto no âmbito local como internacional, entre blocos de países etc.).

No entanto, as reflexões críticas produzidas pelos pesquisadores também influenciam a formação dessa agenda e a ela retornam, explicitando seus limites críticos, exibindo novas contradições ou requalificando melhor algumas delas. É o que atesta a segunda agenda das reformas dos anos 2000, pós-Consenso de Washington, em termos do enfrentamento da pobreza e do caráter estratégico dos programas focalizados. Do mesmo modo, é uma conclusão que também se expressa em termos políticos, quando as agências reconhecem, de forma implícita, a matriz de conflitos e tensões entre blocos em relação, por exemplo, na agenda de defesa do meio ambiente; ou quando a OCDE divulga preocupações relativas às desigualdades no âmbito da redistribuição e do trabalho, em 2013, quando anteriormente orientava a discussão para a temática da pobreza.

A seguir, apresento algumas dimensões preliminares observadas com base nesse levantamento inicial e que permeiam o discurso e a ação das agências.

- Em primeiro lugar, destaca-se o papel contraditório entre o Banco, como instituição financeira, e seu papel em relação ao desenvolvimento humano, na luta contra a pobreza, como patamar de bem-estar. O papel das agências, como operadoras de sistemas de controle dos empréstimos e da dívida, impõe uma disciplina fiscal que compromete tanto os objetivos da agenda social como a soberania dos Estados.

- A difusão de uma normativa de fomento à participação comunitária ou sobre o caráter cooperativo dos Estados, ou entre agentes públicos e privados, esconde assimetrias que produzem a hierarquização entre agentes e blocos de países no interior do quadro dos arranjos cooperativos. Portanto, a normativa da co- 
operação, base da governança, supõe claramente a preexistência do conflito.

- Ressalta-se ainda, no presente, o papel estratégico e contraditório (conflitivo) do acesso a bens públicos naturais, como a água, como direito universal, e a subordinação do acesso a esse bem ou sua distribuição desigual em razão de apropriação privada por grandes corporações, em projetos de energia e prestação de serviços públicos, desrespeitando direitos das populações assentadas nos territórios, além dos riscos para o meio ambiente.

- Considerando-se os recursos intelectuais e financeiros mobilizados pelas agências multilaterais em pesquisas realizadas em países em desenvolvimento, não se pode desconhecer o papel estratégico que elas exercem na influência e na difusão de uma agenda social na produção do conhecimento. O setor de pesquisa do Banco Mundial, por exemplo, aloca um volume significativo de recursos e disponibiliza mais de um milhão de livros e artigos, evidências que demonstram sua grande influência na difusão de ideias quanto à modalidade do desenvolvimento. Ele chega a vender entre US\$ 10 milhões a US\$ 30 milhões por ano em agendas e conhecimento (na geração de ideias), recursos financeiros que podem ultrapassar expectativas de qualquer universidade. Não se pode, portanto, desconsiderar a influência dessas agendas sobre a produção do conhecimento científico em diversos países, mesmo considerando o exercício da crítica social e política.

\section{Referências}

BAAS, S. Participatory institutional development. In: CONFERENCE ON SUSTAINABLE AGRICULTURE AND SAND CONTROL IN GANSU DESERT AREA, Pequim, 1997. Disponível em: <http://www.fao.org/sd/PPdirect/ PPan0012.htm>.

CAVALCANTI, A. C. R. A difusão da agenda urbana das agências multilaterais de desenvolvimento na cidade de Recife. 2008, 213 f. Tese. (Doutorado 
em Desenvolvimento Urbano) - Programa de Pós-Graduação em Desenvolvimento Urbano, Universidade Federal de Pernambuco, Recife, 2008.

HAAS, P. Introduction: epistemic communities and international polity coordination. International Organization, v. 46, n. 1, p. 1-35, 1992.

IVO, Anete B. L. Uma racionalidade constrangida: uma experiência de governança urbana em Salvador. Caderno CRH: Revista do Centro de Recursos Humanos, Salvador, n. 26/27, p. 107-145, 1997.

IVO, Anete B. L. L'expérience de gouvernance urbaine à Salvador de Bahia au Brésil. Les Annales de la Recherche Urbaine. Paris, n. 80/81, p. 55-63, dec. 1998.

IVO, Anete B. L. Metamorfoses da questão democrática: governabilidade e pobreza. Buenos Aires: CLACSO, 2001.

IVO, Anete B. L. The redefinition of the social issue and the rethoric on poverty during the 90. In: CIMADAMORE, A.; HARTLEY, D.; SIQUEIRA, J. (Ed.). The poverty of the state: reconsidering the role of the state in the struggle against global poverty. Buenos Aires: CLACSO/CROP, 2005. p. 65-90. Publicado em português, 2006 e em espanhol, 2009.

IVO, Anete B. L. Desenvolvimento e atores sociais. In: IVO, Anete B. L. et al. (Org.). Dicionário temático desenvolvimento e questão social: 81 problemáticas contemporâneas. São Paulo: Annablume, 2013. p. 102-110.

IVO, Anete B. L. Estado da Arte da Sociologia nos estudos sobre o desenvolvimento. In: MONTEIRO NETO, A. (Org.). Sociologia, política e desenvolvimento. Brasília: IPEA, 2014. v. 2, p. 17-89.

LAVINAS, L. 21st. Century Welfare. New Left Revew, n. 84, p. 5-40, Nov./Dec. 2012.

LAUTIER, B. O consenso sobre as políticas sociais na América Latina, negação da democracia? Caderno CRH: Revista do Centro de Recursos Humanos, Salvador, v. 23, n. 58, p. 353-368, maio/ago. 2010.

OSMONT, A. La 'gouvernance': concept mou, politique ferme. Annales de la Recherche Urbaine, Paris, Plan Urbanisme Construction Architecture, n. 8081, p. 19-26, 1998.

PNUD. Programa das Nações Unidas para o Desenvolvimento. Relatório do desenvolvimento para a erradicação da pobreza. Lisboa: Trinova Editora, 1997.

$\mathrm{SCHINN}, \mathrm{T}$. Formes de division du travail scientifique et convergence intellectuelle: la recherche techico-instrumentale. Revue Française de Sociologie, Paris, v. 41, n. 3, p. 447-473, 2000. 
STERN, N.; FERREIRA, F. The World Bank as 'intellectual actor. In: KAPUR, D. J.; LEWIS, J.; WEBB, R. (Ed.). The World Bank: its first half century. Washington, D.C: Brookings Institutions Press, 1997. v. 2.

WORLD BANK. O Banco Mundial. Disponível em: <www. bancomundial.org. br>. Acesso em: jan. 2014.

\section{Sites consultados}

<http://www.undp.org/content/undp/fr/home/operations/about_us.html> <http://www.futura-sciences.com/magazines/environnement/infos/dico/d/ developpement-durable-banque-mondiale-13364/> $<$ http://www.bancomundial.org.br/> $<$ http://www.ladocumentationfrancaise.fr/dossiers/d000104> $<$ http://www.pnud.org.br/ODM.aspx>

$<$ http://bvsms.saude.gov.br/bvs/publicacoes/declaracao_milenio_nacoes_ unidas.pdf>

<http://www.worldbank.org/en/publication/wdr/wdr-archive>

\section{Notas}

1 Este texto é parte do projeto A reinvenção do desenvolvimento: agências multilaterais do desenvolvimento e produção sociológica, vinculado ao Centro de Estudos e Pesquisas em Humanidades - CRH/ Programa de Pós-Graduação em Ciências Sociais PPGCS/ FFCH/UFBA e apoiado pela Bolsa de Produtividade do CNPq. Brasília, maio 2015 [Relatório final da Bolsa de Produtividade apresentado ao CNPq] e pelo projeto Universal - Edital n. 14, CNPq. Foi publicado em Cadernos do CEAS, n. 235, 2015. Disponível em: <https://cadernosdoceas.ucsal. br/index.php/cadernosdoceas/article/view/28>.

2 Apresento a noção de "consensos relativos" na análise sobre sistemas de local governance. (IVO, 1997)

3 A análise sobre a ação do Banco Mundial e do PNUD em relação à agenda contra a pobreza está desenvolvida em IVO (2001, 2005).

4 Lena Lavinas (2013) apresenta a articulação desses dois paradigmas nos programas de transferência de renda: o do capital humano e o da escolha racional.

5 Agradeço o comentário de Cristiana Mercuri sobre a anterioridade da agenda das ciências sociais sobre as agências. 